\title{
Downregulation of MACC1 inhibits the viability, invasion and migration and induces apoptosis in esophageal carcinoma cells through the phosphatase and tensin homolog/phosphoinositide 3-kinase/protein kinase B signaling pathway
}

\author{
LI-QIANG QIAN $^{1 *}$, XIA-QIN LI ${ }^{2 *}$, PENG-HUI YE ${ }^{1}$, HAO-YUAN SU ${ }^{1}$, GANG WANG ${ }^{1}$, \\ YAN LIU ${ }^{1}$, GEN-HAI SHEN ${ }^{1}$ and QUAN-GEN GAO ${ }^{1}$ \\ ${ }^{1}$ Department of General Surgery, Wujiang No. 1 People's Hospital; ${ }^{2}$ Department of Gynaecology and Obstetrics, \\ Health Center of Songling, Suzhou, Jiangsu 215200, P.R. China
}

Received May 3, 2016; Accepted June 2, 2017

DOI: $10.3892 / 01.2017 .6790$

\begin{abstract}
As an oncogene, MACC1 serves an important function in cancer progression and metastasis. However, the effect of MACC1 in esophageal carcinoma (EC) remains to be fully understood. The present study assessed the association between MACC1 expression and the progression of EC cells. A small interfering (si)RNA was delivered into EC cells to downregulate MACC1 expression. The MTT assay demonstrated that EC cell viability was reduced by siRNA-MACC1. Decreasing MACC1 expression increased the apoptotic rate of EC cells compared with control cells. Transwell and Matrigel assays demonstrated that EC cell migration and invasion, respectively, were downregulated by siRNA-MACC1. Furthermore, knocking down MACC1 suppressed the phosphoinositide 3-kinase (PI3K)/protein kinase B (Akt) signaling pathway by upregulating the expression of phosphatase and tensin homolog (PTEN), a tumor suppressor. The results of the present study revealed that MACC1 expression affected cellular functions of the EC cells through the PTEN/PI3K/Akt signaling pathway. Therefore, MACC1 may potentially serve as a novel biomarker and therapeutic target for EC.
\end{abstract}

\footnotetext{
Correspondence to: Dr Quan-Gen Gao or Dr Gen-Hai Shen, Department of General Surgery, Wujiang No. 1 People's Hospital, 169 Gongyuan Road, Suzhou, Jiangsu 215200, P.R. China

E-mail: wjyyqgg@sohu.com

E-mail: wjyysgh@126.com

${ }^{*}$ Contributed equally
}

Key words: esophageal carcinoma, MACC1, phosphatase and tensin homolog, phosphoinositide 3-kinase, protein kinase B

\section{Introduction}

Esophageal cancer (EC) is associated with an increased mortality rate globally (1). Despite improving treatments, combining surgical resection with chemotherapy or radiotherapy remains a suboptimal treatment option due to early local invasion and systemic metastasis (2-4). The prognosis for EC remains poor and the 5-year overall survival rate in the USA was $4 \%$ in the 1970 s and increased to $14 \%$ in the 1990s (5,6). Previous studies have demonstrated that multiple biological markers may not only facilitate the diagnosis and treatment of EC but may also help to predict early recurrence and clinical outcomes following surgery (7-11).

MACC1 was first identified during a genome-wide screening of human colon cancer tissues and its abnormal expression is associated with the metastasis and recurrence of colon cancer through the regulation of the hepatocyte growth factor-MET proto-oncogene signaling pathway (12). Furthermore, previous studies have revealed that the abnormal expression of MACC1 may be associated with the development and progression of numerous types of solid tumor, including lung $(13,14)$ and gastric cancer (15-18), hepatocellular carcinoma (19-21), breast cancer (22), glioma (23) and colon $(12,24)$ and esophageal cancer (25). These studies suggested that MACC1 may serve as a key biomarker for recurrence, metastasis and patient survival in multiple types of human cancer. To the best of our knowledge, few studies regarding the function of MACC1 in EC have been performed. The present study evaluated the function of MACC1 in EC cells. EC cell viability, invasion, migration and apoptosis potential were assessed by regulating the expression of MACC1.

\section{Materials and methods}

Cell culture and treatment. The human EC cell lines Eca109 and TE1 were purchased from the Type Culture Collection of the Chinese Academy of Sciences (Shanghai, China) and cultured in RPMI-1640 medium containing 10\% fetal bovine serum (FBS) (both from Gibco; Thermo Fisher Scientific, Inc., 
Waltham, MA, USA), $100 \mathrm{IU} / \mathrm{ml}$ penicillin $\mathrm{G}$ and $100 \mu \mathrm{g} / \mathrm{ml}$ streptomycin at $37^{\circ} \mathrm{C}$ in a humidified $5 \% \mathrm{CO}_{2}$ incubator. For the analysis of cell viability and mobility, the Eca109 and TE1 cells were pretreated with $500 \mathrm{nM}$ phosphatase and tensin homolog (PTEN) inhibitor SF1670 at $37^{\circ} \mathrm{C}$ for $30 \mathrm{~min}$ (Gene Operation LLC, Ann Arbor, MI, USA).

Small interfering (si)RNA transfection. siRNA duplexes were synthesized and purified by Suzhou GenePharma LLC (Suzhou, China). siRNA was diluted to $100 \mathrm{nM}$ with serum-free culture medium. The siRNA sequences for MACC1 were as follows: Forward, 5'-AAGAGGGGACGG GGACACGGCTT-3' and reverse, 5'-TTGGCGAACCGG AACAGGGGACG-3'. The transfection of MACC1-siRNA into the experimental Eca109 and TE1 cells was performed using Lipofectamine 2000 reagent (Invitrogen; Thermo Fisher Scientific, Inc.) according to the manufacturer's protocol. The transfection of MACC1-NC (forward, 5'-CCAGTTAAGAAC GTCCCCAAGCG-3' and reverse, 5'-AAGCTTGAGGTCTAG GTAATTTC-3') into the scramble control Eca109 and TE1 cells, was conducted using the same protocol.

Western blot analysis. Protein was extracted from the transfected Eca109 and TE1 cells $\left(1 \times 10^{6}\right)$ cells using radioimmunoprecipitation assay lysis buffer containing 1/100 phenylmethanesulfonyl fluoride (P0013; Beyotime Institute of Biotechnology, Haimen, China) at $0-4^{\circ} \mathrm{C}$ for $30 \mathrm{~min}$. The supernatant was collected at $3,000 \mathrm{x} \mathrm{g}$ in $4^{\circ} \mathrm{C}$ for $30 \mathrm{~min}$. The total protein concentration was determined using the bicinchoninic acid method. Protein ( $20 \mu \mathrm{g} /$ lane) was separated using SDS-PAGE on a $10 \%$ gel and subsequently transferred to polyvinylidene fluoride membranes. The membranes were blocked with 5\% nonfat milk at room temperature for $1 \mathrm{~h}$ and then incubated overnight at $4{ }^{\circ} \mathrm{C}$ with primary antibodies. The membranes were then washed three times in TBS containing $0.05 \%$ Tween-20 and incubated with AP-labeled goat anti-mouse/rabbit IgG (A0258/A0239; 1:5,000; Beyotime Institute of Biotechnology) for $2 \mathrm{~h}$ at room temperature. The secondary antibodies were detected using an enhanced chemiluminescence kit according to the manufacturer's protocol (Pierce; Thermo Fisher Scientific, Inc.). The primary antibodies were goat polyclonal anti-MACC1 (catalog no. HPA020081; dilution, 1:1,000; Sigma-Aldrich; Merck KGaA, Darmstadt, Germany), rabbit monoclonal anti-caspase-3 (catalog no. CST9662), rabbit monoclonal anti-cleaved caspase-3 (catalog no. 9664), rabbit monoclonal anti-Bcl-2 (catalog no. 2872) and rabbit monoclonal anti-Bax (catalog no. 5023) (dilution, 1:1,000; all from Cell Signaling Technology, Inc., Danvers, MA, USA), rabbit monoclonal anti-PTEN (catalog no. ab32199), mouse monoclonal anti-PCNA (catalog no. 29), rabbit monoclonal anti-Akt (pan; catalog no. 85683), rabbit monoclonal anti-Akt (phospho S473; catalog no. 81283) (dilution, 1:1,000; all from Abcam, Cambridge, UK), and mouse monoclonal anti-GAPDH (catalog no. KC-5G5; dilution, 1:5,000; Kangcheng Biotechnology Co., Ltd., Nanjing, China). GAPDH protein was used as the internal control.

Cell viability assay. The viability of Eca109 and TE1 cells under the aforementioned pretreatments was evaluated using an MTT assay. Eca109 and TE1 cells were seeded onto 96-well plates (8,000 cells/well) with RPMI-1640 medium and transfected with the siRNA vectors as aforementioned at $37^{\circ} \mathrm{C}$. Following incubation for $48 \mathrm{~h}$ at $37^{\circ} \mathrm{C}, 5 \mathrm{mg} / \mathrm{ml}$ MTT was added to each well and the cells were incubated for a further $4 \mathrm{~h}$ at $37^{\circ} \mathrm{C}$. Following the addition of $150 \mathrm{ml}$ dimethyl sulfoxide to each well, the absorbance was measured at $490 \mathrm{~nm}$ (ELX800; BioTek Instruments, Inc., Winooski, VT, USA). The experiment was repeated three times.

Soft agar colony formation assay. To assess colony formation, Eca109 and TE1 cells were collected following treatment, and $1 \times 10^{4}$ cells were mixed with $0.6 \%$ agar solution in RPMI- 1640 medium containing $20 \% \mathrm{FBS}$ and placed on a $1.2 \%$ agar layer in 6-well tissue culture plates. Following solidification of the gel, the cells were incubated for 2-3 weeks in a $5 \% \mathrm{CO}_{2}$, humidified incubator at $37^{\circ} \mathrm{C}$ until colonies formed, during which time, RPMI-1640 supplemented with $10 \%$ FBS was changed every 3 or 4 days. The colonies containing $>50$ cells were subsequently counted using a light microscope. Clones were counted in 10 random fields at x100 magnification and the mean \pm standard deviation (SD) was calculated. The experiment was repeated three times.

Cell migration and invasion assays. Eca109 and TE1 cell migration and invasion were evaluated using Transwell assays (EMD Millipore, Billerica, MA, USA), according to the manufacturer's protocol. For the invasion assay, $5 \times 10^{4}$ cells in total were seeded onto a Transwell insert (pore size, $8 \mathrm{~mm}$ ) coated with extracellular matrix $(50 \mathrm{mg} / \mathrm{l}$ Matrigel, 1:6 dilution with serum-free medium; BD Biosciences, Franklin Lakes, NJ, USA). Subsequently, $100 \mu 1$ serum-free RPMI-1640 medium containing $10 \mathrm{~g} / 1$ bovine serum albumin (ST023; Beyotime Institute of Biotechnology) was added to the upper chamber, and $500 \mu \mathrm{l}$ complete culture medium was added to the lower chamber. Cells were incubated at $37^{\circ} \mathrm{C}$ for $24 \mathrm{~h}$ for both the migration and invasion assays. For the migration assay, $5 \times 10^{4}$ Eca109 and TE1 cells were seeded onto a Transwell insert, which was not coated with Matrigel. Following incubation at $37^{\circ} \mathrm{C}$ for $24 \mathrm{~h}$, the cells adherent to the upper surface of the filter were removed using a cotton applicator and stained with $0.5 \%$ crystal violet at room temperature for $15 \mathrm{~min}$. Cell numbers were counted in 10 random fields at $\mathrm{x} 100$ magnification by light microscope. The values obtained were calculating the mean \pm standard deviation (SD) from triplicates of each assay.

Apoptosis assays. Eca109 and TE1 cells were seeded onto 6-well plates $\left(5 \times 10^{5}\right.$ cells/well) with RPMI-1640 complete culture medium. Following $48 \mathrm{~h}$ of transfection as aforementioned, the cells were collected, including the supernatant of the culture medium, by centrifugation at $250 \mathrm{x}$ g for $3 \mathrm{~min}$ at room temperature, and the cells in each well were washed with PBS twice. The cells were subsequently incubated at room temperature with $5 \mu \mathrm{l}$ Annexin V-fluorescein isothiocyanate in $195 \mu \mathrm{l}$ binding buffer (catalog no. C1063; Beyotime Institute of Biotechnology) in darkness for $10 \mathrm{~min}$. Cells were centrifuged at $250 \mathrm{x}$ g for $5 \mathrm{~min}$ at room temperature and resuspended in $190 \mathrm{ml}$ binding buffer and $10 \mathrm{ml}$ propidium iodide. All samples were analyzed for apoptosis using the BD FACSVerse ${ }^{\mathrm{TM}}$ (651156) flow cytometer (BD Biosciences). 


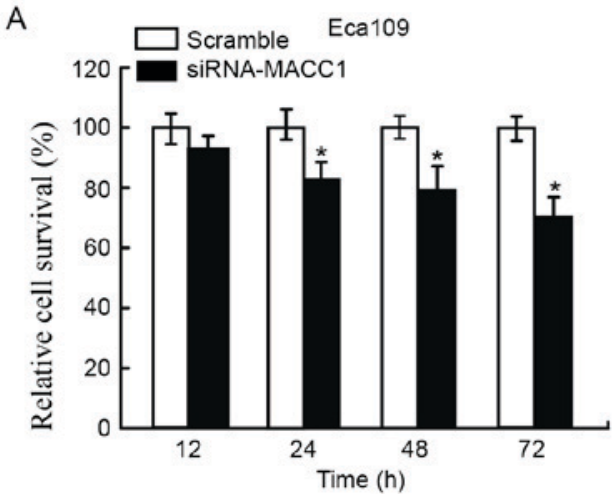

B
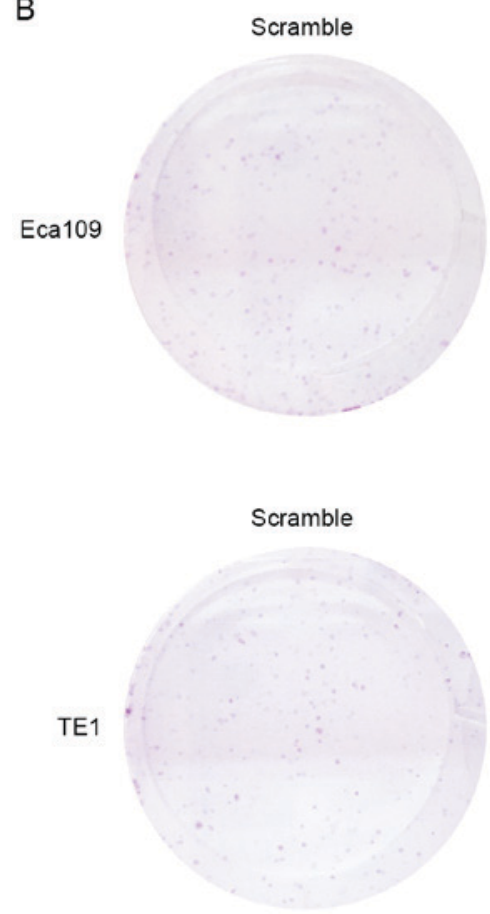
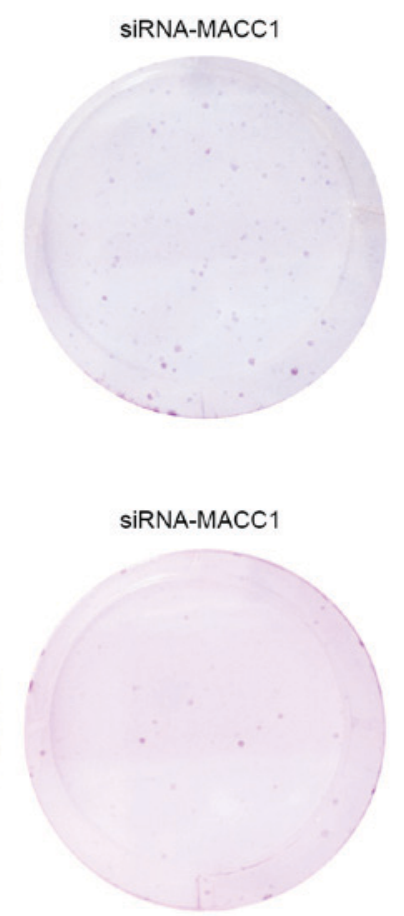
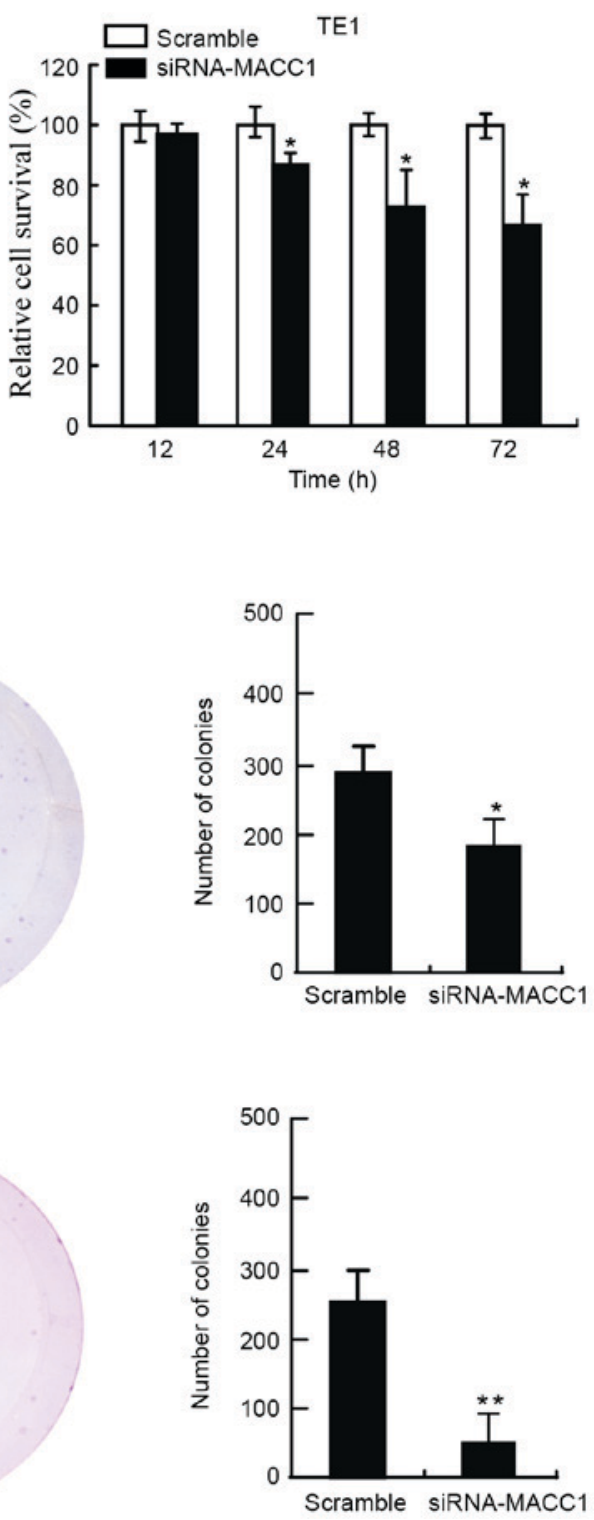

Figure 1. Downregulation of MACC1 significantly inhibits the viability and colony formation of EC cells in vitro. (A) EC cell viability was assessed using an MTT assay. Eca109 and TE1 cells were pretreated with siRNA-MACC1 and the scramble control siRNA for 12, 24, 48 or $72 \mathrm{~h}$. (B) The colony formation of Eca109 and TE1 cells with downregulated MACC1 expression was evaluated using a soft agar colony formation assay. ${ }^{*} \mathrm{P}<0.05,{ }^{* *} \mathrm{P}<0.01$ vs. scramble control. EC, esophageal cancer; si, small interfering.

The BD FACSuite ${ }^{\mathrm{TM}}$ software (11.10; BD Biosciences) was used to analyze the data. The experiment was repeated three times.

Immunocytochemistry. Eca109 and TE1 cells $\left(2 \times 10^{5}\right)$ were cultured on coverslips in 6-well plates with RPMI-1640 complete culture medium and transfected with MACC1-siRNA as aforementioned. Following $48 \mathrm{~h}$ of culture, the cells were washed with PBS, fixed with $2 \% \mathrm{w} / \mathrm{v}$ paraformaldehyde for $15 \mathrm{~min}$ and permeabilized with $1 \% \mathrm{v} / \mathrm{v}$ Triton X-100 for $10 \mathrm{~min}$ at room temperature. Subsequently, blocking was achieved through incubation with $10 \% \mathrm{w} / \mathrm{v}$ normal goat serum (SP Kit-B2; Fuzhou Maixin Biotech. Co., Ltd., Fuzhou, China) in PBS at room temperature for $1 \mathrm{~h}$. Cells were then incubated with MACC (catalog no. HPA020081; dilution, 1:100; Sigma-Aldrich; Merck KGaA), PTEN (catalog no. ab32199; dilution, 1:100) and p-Akt (phospho
S473; catalog no. ab81283; dilution, 1:200) (both from Abcam) primary antibodies at $4^{\circ} \mathrm{C}$ overnight. Subsequently, the cells were washed with PBS, and incubated for $1 \mathrm{~h}$ with Cy3-labeled secondary antibody (catalog no. A0516; dilution, 1:400; Beyotime Institute of Biotechnology) at room temperature, and subsequently counterstained with DAPI $(1 \mu \mathrm{g} / \mathrm{ml}$ ) for $5 \mathrm{~min}$ at room temperature (Sigma-Aldrich; Merck KGaA). Images of the immunostained cells were obtained using a fluorescent microscope (x200 magnification).

Statistical analysis. All statistical analyses were performed using SPSS 18.0 statistical software (SPSS, Inc., Chicago, IL, USA). The results are presented as the mean \pm SD as appropriate. Student's t-test was used to compare viability, migration, invasion and apoptosis between the groups. $\mathrm{P}<0.05$ was considered to indicate a statistically significant difference. 

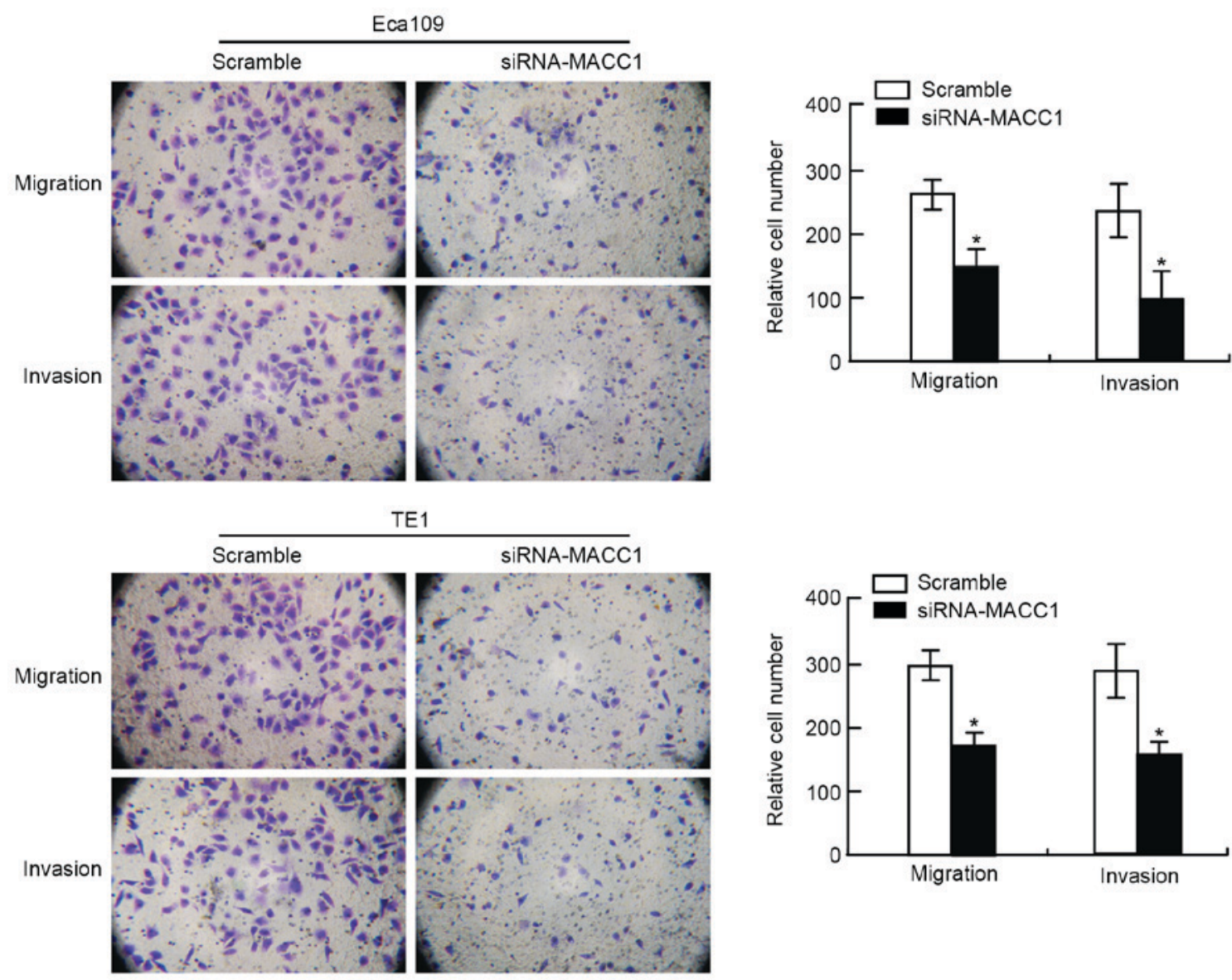

Figure 2. Downregulation of MACC1 contributes to the inhibition of the migration and invasion of esophageal cancer cells in vitro. The migration and invasion of Eca109 and TE1 cells with downregulated MACC1 expression were assessed using a Matrigel and Transwell assay, respectively. Data were presented as the mean \pm standard deviation, as derived from three independent experiments. ${ }^{*} \mathrm{P}<0.05$ vs. scramble control. si, small interfering. Magification, $\mathrm{x} 100$.

\section{Results}

Decreased MACC1 expression significantly inhibits EC cell viability in vitro. Cell viability was assessed using an MTT assay. The present study evaluated four time-points $(12,24,48$ and $72 \mathrm{~h})$ following transfection of the EC cells with siRNA-MACC1. The results revealed that EC cells transfected with siRNA-MACC1 exhibited significantly decreased cell viability compared with those transfected with the scramble control $(\mathrm{P}<0.05$; Fig. 1A). The inhibition rate of siRNA-MACC1 on EC cell viability was $5-35 \%$. The present study evaluated the rate of colony formation of the EC cells 2 weeks following treatment. The results suggested that the EC cells transfected with siRNA-MACC1 formed fewer colonies compared with those transfected with the scramble control $(\mathrm{P}<0.05, \mathrm{P}<0.01$; Fig. 1B). The results of the present study suggested that siRNA-MACC1 inhibited the viability and neoplastic capacity of EC cells in vitro.

Downregulating MACCl contributes to the inhibition of migration and invasion of EC cells in vitro. To assess the effect of siRNA-MACC1 on cell motility, the EC cells underwent migration and invasion assays following transfection. The results demonstrated that the number of migratory and invasive cells in the siRNA-MACC1-transfected EC cell group was significantly decreased compared with that in the scramble control EC cell group $(\mathrm{P}<0.05 ;$ Fig. 2). These results suggested that the knockdown of MACC1 contributed to the inhibition of migration and invasion of EC cells in vitro. The present study suggested that MACC1 serves a key function in the regulation of EC cell motility, including invasion and metastasis.

Knockdown of MACCl markedly induces apoptosis of EC cells in vitro. The apoptosis assay revealed that the apoptotic rate of the siRNA-MACC1-transfected Eca109 cells $(9.71 \pm 2.89 \%)$ was increased compared with that of the scramble control Eca109 cells $(4.79 \pm 1.65 \%)$; that of the siRNA-MACC1-transfected TE1 cells $(15.32 \pm 2.45 \%)$ was increased compared with that of the scramble control TE1 cells $(6.08 \pm 0.87 \%)$. The difference in apoptotic rate between these groups was statistically significant in the two cell lines $(\mathrm{P}<0.05$; Fig. $3 \mathrm{~A})$. The expression of B-cell lymphoma 2 (BCL2), an anti-apoptotic indicator, was downregulated, and the expression of apoptosis-associated cleaved caspase- 3 and BCL2 associated X was upregulated, in siRNA-MACC1-transfected EC cells compared with that in the scramble control EC cells (Fig. 3B). The present study demonstrated that downregulating MACC1 significantly induced apoptosis in EC cells in vitro.

Decreasing MACCl expression suppresses the PTEN/phosphoinositide 3-kinase (PI3K)/protein kinase B (Akt) signaling pathway of EC cells. The present study evaluated the effect 
A
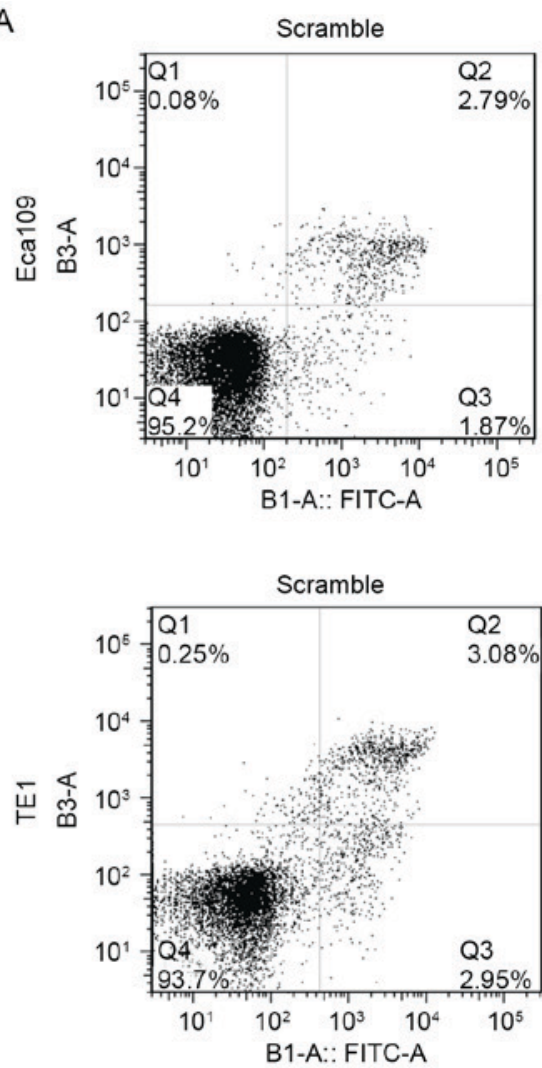
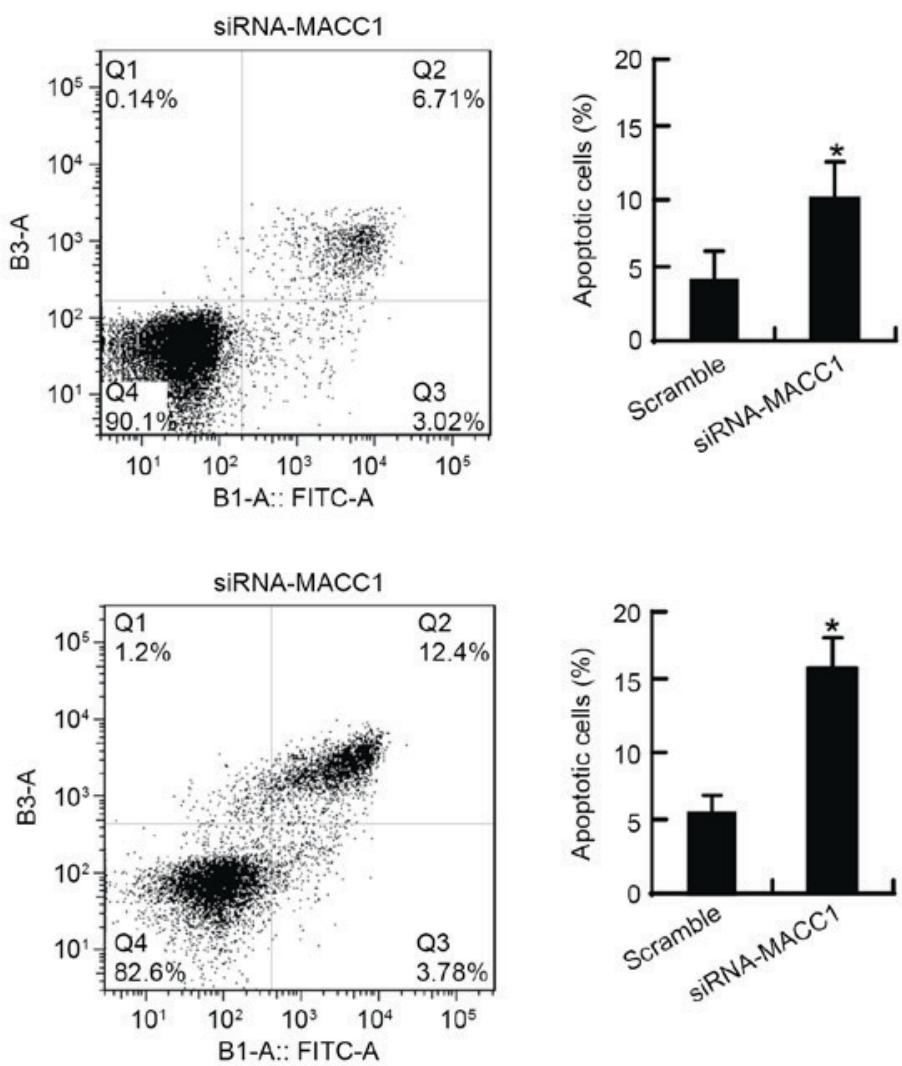

B
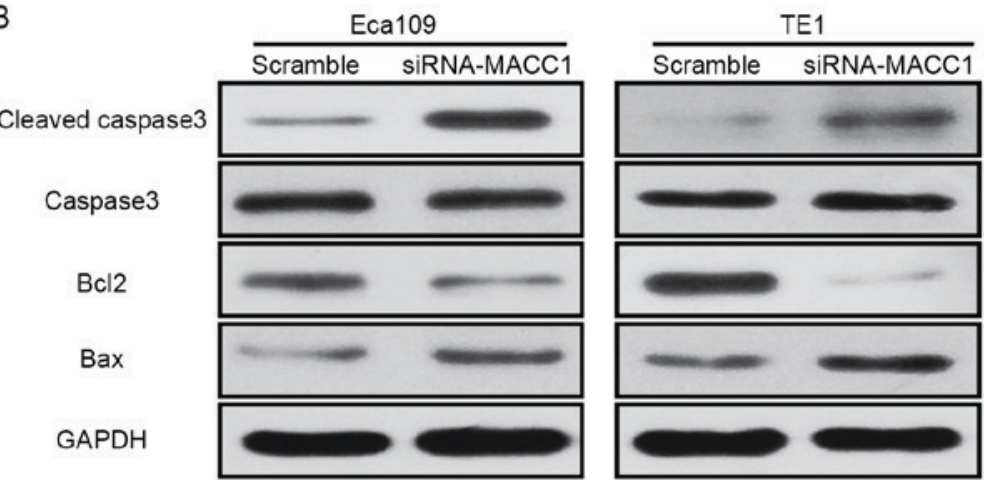

Figure 3. Downregulating MACC1 expression induces esophageal cancer cell apoptosis in vitro. (A) The apoptotic potential induced by siRNA-MACC1 was measured using flow cytometry. (B) The expression of apoptosis-associated proteins in Eca109 and TE1 cells with downregulated MACC1 expression was detected using western blot analysis. " $\mathrm{P}<0.05$ vs. scramble control. si, small interfering; Bcl2, B-cell lymphoma 2; bax, Bcl2 associated X; FITC, fluorescein isothiocyanate.

of downregulating MACC1 expression on PTEN and the PI3K/Akt signaling pathway in EC cells (Fig. 4). The siRNA-MACC1-transfected EC cells revealed a significant decrease in MACC1 protein expression compared with that in the scramble control EC cells (Fig. 4B). In the EC cells in which MACC1 expression was downregulated, compared with the scramble control EC cells, the expression of PTEN was increased, the expression of total Akt remained unaltered, and the expression of phosphorylated (p)Akt and proliferating cell nuclear antigen was decreased (Fig. 4B). The present study obtained similar results from immunofluorescence experiments (Fig. 4A). Furthermore, the present study used the PTEN inhibitor SF1670 to assess the effect of PTEN on signaling pathways in the EC cells. The results revealed that treatment with 500 nM SF1670 decreased the inhibition of viability, mobility, and phosphorylation of Akt in EC cells (Fig. 5). The results of the present study suggested that decreasing MACC1 expression affected the expression of PTEN and the phosphorylation of Akt in the EC cells, which suggested that MACC1 represents a potential oncoprotein and a promoting factor for the activation of the PTEN/PI3K/Akt signaling pathway in these cells. Furthermore, decreasing MACC1 expression in the EC cells may have facilitated the regulation of the PI3K/Akt signaling pathway by PTEN and helped PTEN function as a tumor suppressor.

\section{Discussion}

Among types of cancer, EC is associated with the sixth highest global mortality rate in 1990s (3). Although research 
A
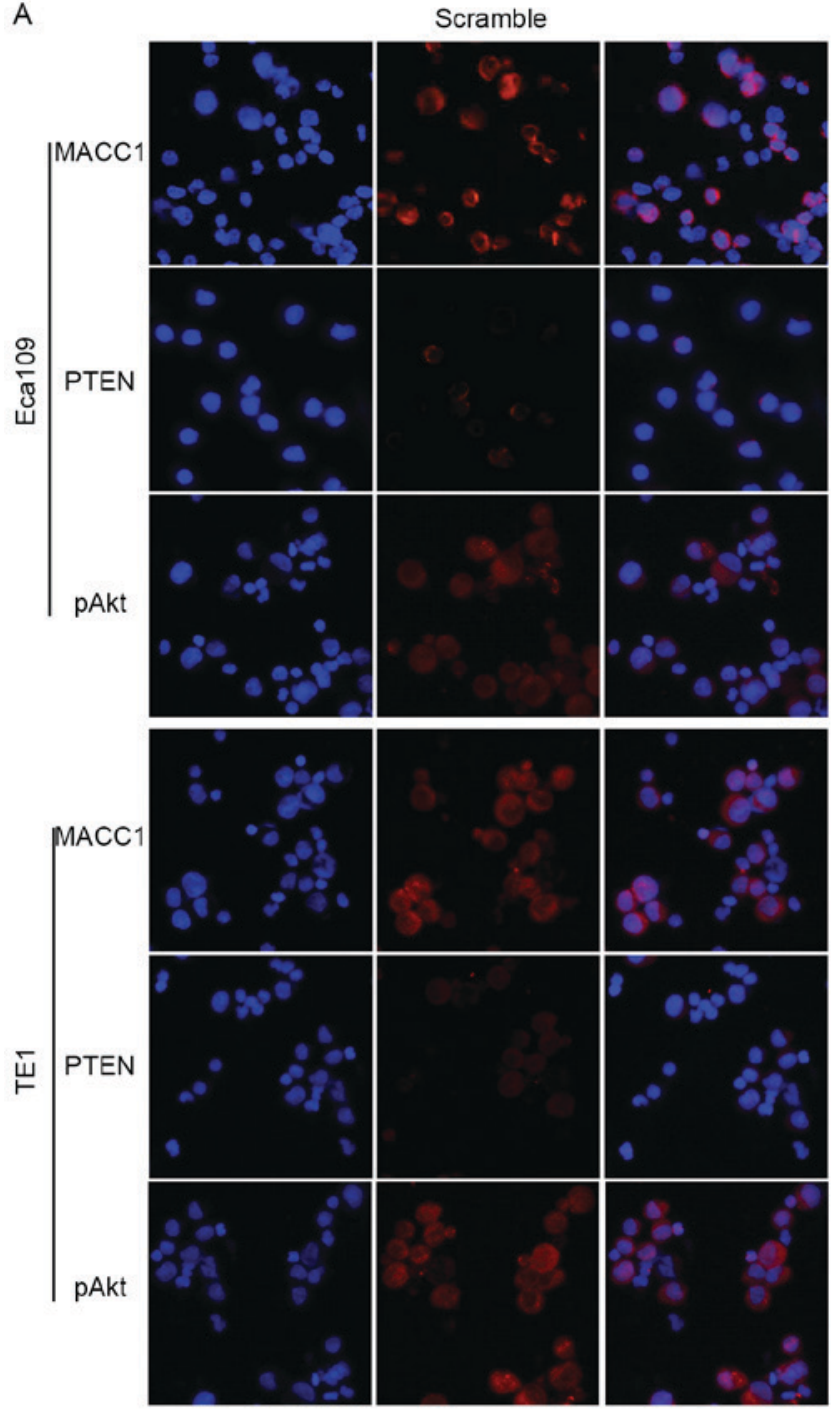

B

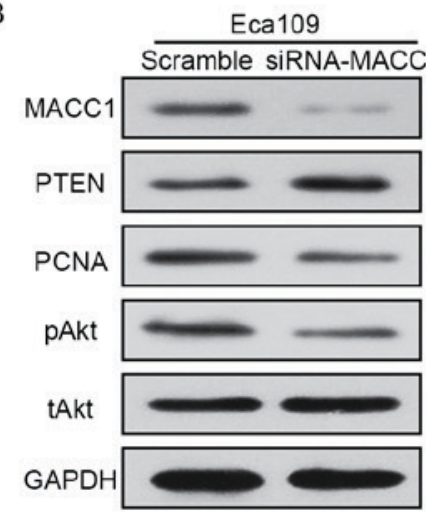

TE1

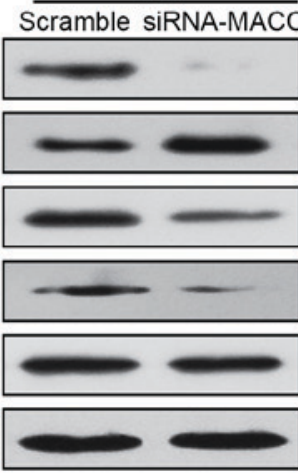

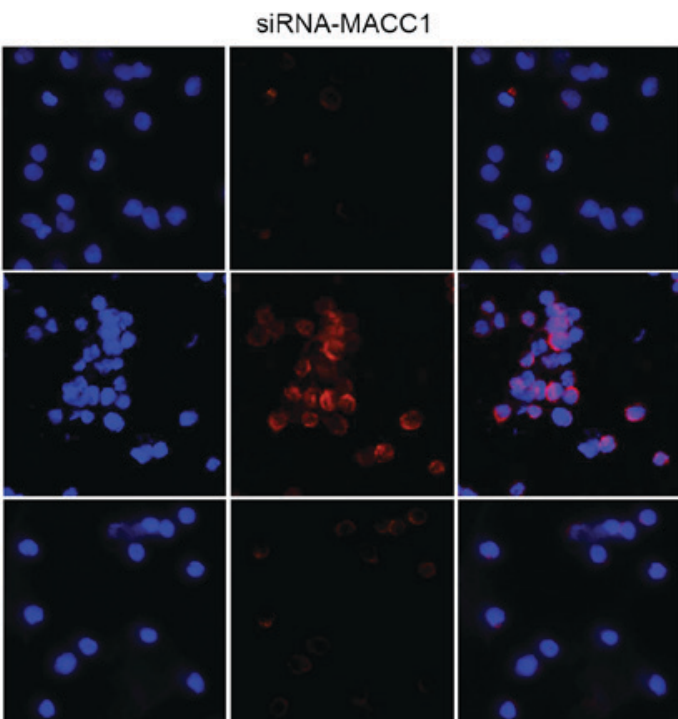

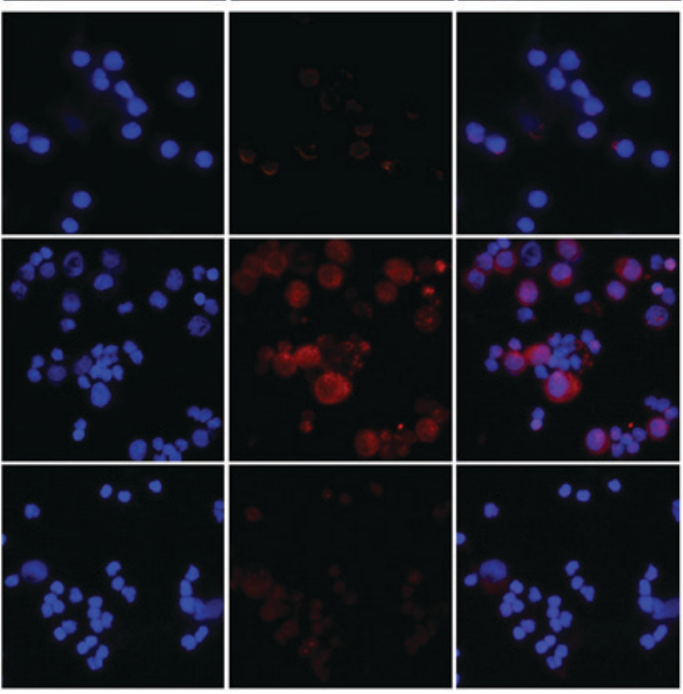

Figure 4. Downregulating MACC1 expression suppresses the PTEN/PI3K/Akt signaling pathway in esophageal cancer cells. (A) MACC1, PTEN and pAkt expression was detected using immunofluorescence (magnification x200). (B) The protein expression of MACC1, PTEN, tAkt, pAkt and PCNA in Eca109 and TE1 cells with downregulated MACC1 expression were detected using western blot analysis. PTEN, phosphatase and tensin homolog; PI3K, phosphoinositide 3-kinase; Akt, protein kinase B; p, phosphorylated; t, total; PCNA, proliferating cell nuclear antigen; si, small interfering.

and novel molecular targets have improved early diagnosis and therapeutic options, and provided less invasive surgery options, the 5-year survival rate for EC remains low due to increased rates of metastasis and recurrence (5).

EC cells migrate from the primary site to distant sites through the bloodstream or the lymphatic system, a crucial factor in the prognosis of EC. MACC1, first identified as a colon cancer oncogene, potentially functions as an early diagnosis biomarker and is associated with the progression of multiple solid tumors (12-28). Stein et al (12) demonstrated that MACC1 upregulation was associated with benign-malignant tumor transition. Wang et al (29) revealed that inhibiting 

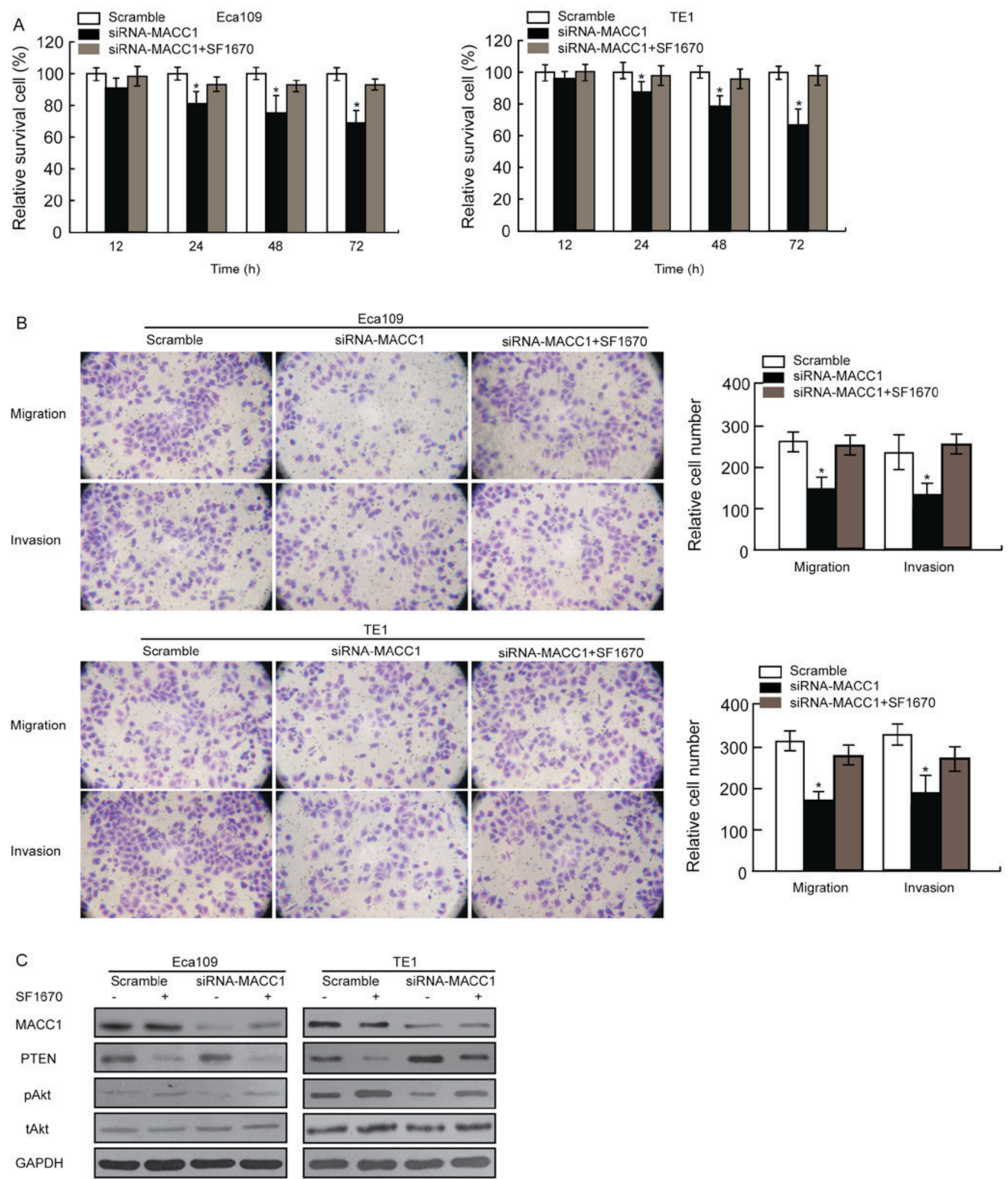

Figure 5. PTEN inhibitor SF1670 affects viability, mobility and the PTEN/PI3 K/Akt signaling pathway in EC cells. (A) EC cell viability was assessed using an MTT assay. Eca109 and TE1 cells were pretreated with the scramble control siRNA and siRNA-MACC1 with or without 500 nM SF1670 for 12, 24, 48 or $72 \mathrm{~h}$. (B) The migration and invasion of Eca109 and TE1 cells with downregulated MACC1 expression with or without $500 \mathrm{nM}$ SF1670 were evaluated using a Matrigel or Transwell assay. Data were presented as the mean \pm standard deviation, as derived from three independent experiments. (C) The expression of MACC1, PTEN, tAkt and pAkt proteins in Eca109 and TE1 cells with downregulated MACC1 expression with or without $500 \mathrm{nM}$ SF1670 was detected using western blot analysis. "P<0.05 vs. scramble control. PTEN, phosphatase and tensin homolog; PI3K, phosphoinositide 3-kinase; Akt, protein kinase B; EC, esophageal cancer; si, small interfering; $\mathrm{t}$, total; $\mathrm{p}$, phosphorylated. Magnification, x100.

MACC1 significantly inhibited the proliferation and migration of pancreatic cancer cells. However, the effect of MACC1 expression in EC cells remains unclear. Using MACC1-siRNA, the present study assessed the expression of MACC1 in EC 
cells and its effect on the viability, migration, invasion and apoptosis of the EC cells. The results revealed that inhibiting MACC1 expression in EC cells decreased viability and affected migration and invasion, which are key processes in metastasis. Furthermore, downregulating MACC1 contributed to the induction of EC cell apoptosis. These results suggested that increased MACC1 expression may be associated with the survival and aggressiveness of EC cells and may serve an important function in their metastasis.

Previous studies have suggested that MACC1 is associated with the Akt and Ras/EPH receptor B2 signaling pathways (28-30). Zhang et al (28) demonstrated that MACC1 expression may affect the PI3K/Akt signaling pathway and the protein expression of matrix metallopeptidase (MMP)2 and MMP9. Meng et al (30) revealed that pAkt was a key target gene of MACC1, and that pAkt expression was significantly suppressed by MACC1 downregulation in nasopharyngeal carcinoma cells. In the present study, downregulating MACC1 expression increased the expression of PTEN and decreased the phosphorylation of Akt in EC cells. PTEN, a tumor suppressor gene with numerous functions in multiple tissues, serves as a central negative regulator of the PI3K/Akt signaling pathway by dephosphorylating the PI (31) and P3 of PI3K and regulating downstream signals (32). The present study demonstrated that downregulating MACC1 decreased EC cell viability and mobility. The present study also demonstrated that the PTEN inhibitor SF1670 not only decreased the inhibitory effect of siRNA-MACC1 on viability and mobility, but also affected the PTEN/PI3K/Akt signaling pathway in EC cells. These results suggested that MACC1 represents a potential oncoprotein, and a promoting factor for the activation of the PTEN/PI3K/Akt signaling pathway in EC cells. Furthermore, decreasing MACC1 expression in the EC cells may have facilitated the regulation of the PI3K/Akt signaling pathway by PTEN and helped PTEN function as a tumor suppressor.

The present study suggested that MACC1 abnormal expression may affect the PTEN/PI3K/Akt signaling pathway and is thereby crucial for the viability, migration, invasion and apoptosis of EC cells. These results suggested that MACC1 may potentially serve as a therapeutic target for EC. However, the molecular mechanisms underlying the function of MACC1 in the PTEN/PI3K/Akt signaling pathway remain to be fully understood. Further studies are required to clarify the genetic features of MACC1 and its potential as a target in antitumor therapy for EC.

\section{References}

1. Zhang YQ, Zhang JJ, Song HJ and Li DW: Expression and prognostic influence of NF- $\mathrm{KB}$ and EGFR in esophageal cancer. Genet Mol Res 14: 16819-16826, 2015.

2. Jemal A, Siegel R, Ward E, Hao Y, Xu J, Murray T and Thun MJ: Cancer statistics, 2008. CA Cancer J Clin 58: 71-96, 2008.

3. Pisani P, Parkin DM, Bray F and Ferlay J: Erratum: Estimates of the worldwide mortality from 25 cancers in 1990. Int. J. Cancer, 83, 18-29 (1999). Int J Cancer 83: 870-873, 1999.

4. Collard JM, Otte JB, Fiasse R, Laterre PF, De Kock M, Longueville J, Glineur D, Romagnoli R, Reynaert M and Kestens PJ: Skeletonizing en bloc esophagectomy for cancer. Ann Surg 234: 25-32, 2001.

5. Enzinger PC and Mayer RJ: Esophageal cancer. N Engl J Med 349: 2241-2252, 2003.
6. Kamangar F, Dores GM and Anderson WF: Patterns of cancer incidence, mortality, and prevalence across five continents: Defining priorities to reduce cancer disparities in different geographic regions of the world. J Clin Oncol 24: 2137-2150, 2006.

7. Blanchard P, Quero L and Hennequin C: Prognostic and predictive factors of oesophageal carcinoma. Bull Cancer 96: 379-389, 2009 (In French).

8. Li C, Li Z, Zhu M, Zhao T, Chen L, Ji W, Chen H and Su C: Clinicopathological and prognostic significance of survivin over-expression in patients with esophageal squamous cell carcinoma: A meta-analysis. PLoS One 7: e44764, 2012.

9. Lin YC, Wu MY, Li DR, Wu XY and Zheng RM: Prognostic and clinicopathological features of E-cadherin, alpha-catenin, beta-catenin, gamma-catenin and cyclin D1 expression in human esophageal squamous cell carcinoma. World J Gastroenterol 10: 3235-3239, 2004.

10. Michaylira CZ, Wong GS, Miller CG, Gutierrez CM, Nakagawa H, Hammond R, Klein-Szanto AJ, Lee JS, Kim SB, Herlyn M, et al: Periostin, a cell adhesion molecule, facilitates invasion in the tumor microenvironment and annotates a novel tumor-invasive signature in esophageal cancer. Cancer Res 70: 5281-5292, 2010.

11. Chen M, Cai E, Huang J, Yu P and Li K: Prognostic value of vascular endothelial growth factor expression in patients with esophageal cancer: A systematic review and meta-analysis. Cancer Epidemiol Biomarkers Prev 21: 1126-1134, 2012.

12. Stein U, Walther W, Arlt F, Schwabe H, Smith J, Fichtner I, Birchmeier W and Schlag PM: MACC1, a newly identified key regulator of HGF-MET signaling, predicts colon cancer metastasis. Nat Med 15: 59-67, 2009.

13. Wang Z, Cai M, Weng Y, Zhang F, Meng D, Song J, Zhou H and Xie Z: Circulating MACC1 as a novel diagnostic and prognostic biomarker for nonsmall cell lung cancer. J Cancer Res Clin Oncol 141: 1353-1361, 2015.

14. Chundong G, Uramoto H, Onitsuka T, Shimokawa H, Iwanami T, Nakagawa M, Oyama T and Tanaka F: Molecular diagnosis of MACC1 status in lung adenocarcinoma by immunohistochemical analysis. Anticancer Res 31: 1141-1145, 2011.

15. Shirahata A, Sakata M, Kitamura Y, Sakuraba K, Yokomizo K, Goto T, Mizukami H, Saito M, Ishibashi K, Kigawa G, et al: MACC 1 as a marker for peritoneal-disseminated gastric carcinoma. Anticancer Res 30: 3441-3444, 2010.

16. Burock S, Herrmann P, Wendler I, Niederstrasser M, Wernecke KD and Stein U: Circulating metastasis associated in colon cancer 1 transcripts in gastric cancer patient plasma as diagnostic and prognostic biomarker. World J Gastroenterol 21: 333-341, 2015.

17. Yang T, He W, Cui F, Xia J, Zhou R, Wu Z, Zhao Y and Shi M: MACC1 mediates acetylcholine-induced invasion and migration by human gastric cancer cells. Oncotarget 7: 18085-18094, 2016.

18. Sun L, Duan J, Jiang Y, Wang L, Huang N, Lin L, Liao Y and Liao W: Metastasis-associated in colon cancer-1 upregulates vascular endothelial growth factor-C/D to promote lymphangiogenesis in human gastric cancer. Cancer Lett 357: 242-253, 2015.

19. Qu JH, Chang XJ, Lu YY, Bai WL, Chen Y, Zhou L, Zeng Z, Wang CP, An LJ, Hao LY, et al: Overexpression of metastasis-associated in colon cancer 1 predicts a poor outcome of hepatitis B virus-related hepatocellular carcinoma. World J Gastroenterol 18: 2995-3003, 2012.

20. Shirahata A, Fan W, Sakuraba K, Yokomizo K, Goto T, Mizukami H, Saito M, Ishibashi K, Kigawa G, Nemoto H, et al: MACC 1 as a marker for vascular invasive hepatocellular carcinoma. Anticancer Res 31: 777-780, 2011.

21. Yao Y, Dou C, Lu Z, Zheng X and Liu Q: MACC1 suppresses cell apoptosis in hepatocellular carcinoma by targeting the HGF/c-MET/AKT pathway. Cell Physiol Biochem 35: 983-996, 2015.

22. Huang Y, Zhang H, Cai J, Fang L, Wu J, Ye C, Zhu X and Li M: Overexpression of MACC1 and Its significance in human breast cancer progression. Cell Biosci 3: 16, 2013.

23. Shang C, Hong Y, Guo Y, Liu YH and Xue YX: Influence of the MACC1 gene on sensitivity to chemotherapy in human U251 glioblastoma cells. Asian Pac J Cancer Prev 16: 195-199, 2015.

24. Isella C, Mellano A, Galimi F, Petti C, Capussotti L, De Simone M, Bertotti A, Medico E and Muratore A: MACC1 mRNA levels predict cancer recurrence after resection of colorectal cancer liver metastases. Ann Surg 257: 1089-1095, 2013. 
25. Zhu M, Xu Y, Mao X, Gao Y, Shao L and Yan F: Overexpression of metastasis-associated in colon cancer-1 associated with poor prognosis in patients with esophageal cancer. Pathol Oncol Res 19: 749-753, 2013.

26. Rikitake Y, Kawashima S, Yamashita T, Ueyama T, Ishido S, Hotta H, Hirata Ki and Yokoyama M: Lysophosphatidylcholine inhibits endothelial cell migration and proliferation via inhibition of the extracellular signal-regulated kinase pathway, Arterioscler Thromb Vasc Biol 20: 1006-1012, 2000.

27. Wang L, Wu Y, Lin L, Liu P, Huang H, Liao W, Zheng D, Zuo Q, Sun L, Huang N, et al: Metastasis associated in colon cancer-1 upregulation predicts a poor prognosis of gastric cancer, and promotes tumor cell proliferation and invasion. Int J Cancer 133 1419-1430, 2013

28. Zhang K, Tian F, Zhang Y, Zhu Q, Xue N, Zhu H, Wang H and Guo X: MACC1 is involved in the regulation of proliferation, colony formation, invasion ability, cell cycle distribution, apoptosis and tumorigenicity by altering Akt signaling pathway in human osteosarcoma. Tumour Biol 35: 2537-2548, 2014.
29. Wang G, Kang MX, Lu WJ, Chen Y, Zhang B and Wu YL: MACC1: A potential molecule associated with pancreatic cancer metastasis and chemoresistance. Oncol Lett 4: 783-791, 2012.

30. Meng F, Li H, Shi H, Yang Q, Zhang F, Yang Y, Kang L, Zhen T, Dai S, Dong Y and Han A: MACC1 downregulation inhibits proliferation and tumourigenicity of nasopharyngeal carcinoma cells through Akt/ $\beta$-catenin signaling pathway. PLoS One 8: e60821, 2013.

31. Aravalli RN, Steer CJ and Cressman EN: Molecular mechanisms of hepatocellular carcinoma. Hepatology 48: 2047-2063, 2008.

32. Baker SJ: PTEN enters the nuclear age. Cell 128: 25-28, 2007. 